\title{
The features of norms formed in constructing student-generated drawings to explain physics phenomena
}

\begin{abstract}
Student-generated drawing is a useful strategy to construct students' scientific ideas. For exploring ways to support student-generated drawing, this study focused on the perspective of 'Norms' - shared behaviour patterns desirable in a community. We investigated what norms were formed and how they emerged when students made their drawings to explain phenomena. Data were collected from classroom observations, interviews and students' artefacts from five physics lessons in a primary school gifted program. The data were analysed based on three essential features of norms: justifiability, sharing and behaviours. Consequently, two main norms were reported with four sub-norms in terms of two processes of drawing: meaning-making and representing. First, to show invisible mechanism, 'explaining why' was emphasised as a main norm of the meaning-making process. This norm was shared in group discussions and drawings by interacting with two sub-norms that supported students to interpret phenomena with 'key science concepts' at a 'particle level'. Second, 'telling a story visually' was another main norm of the representing process. This norm was formed with its two sub-norms that encouraged students to visualise ideas with 'their own symbols' in ways that were 'easy to understand'. These results indicate that norms can guide desirable directions for students to construct and visualise ideas in scientific drawings.
\end{abstract}

Keywords: student-generated drawing; norms; meaning-making; representation

\section{Introduction}

One of the important goals of science is to explain natural phenomena by identifying mechanisms of the world-as-experienced (McCain, 2015). In science education, it has been emphasised that students need to explore the reasons for a phenomenon and establish their own explanations (Braaten \& Windschitl, 2011). With the emphasis on epistemic aspects of generating scientific knowledge, the construction of scientific explanations has been considered especially important as an epistemic practice that students can experience in 
science classrooms (Sandoval, 2003).

In constructing scientific explanations, various types of representations are used to depict phenomena (Yeo \& Gilbert, 2014). Each representation reveals different aspects of the same phenomenon (Ainsworth, 2006). Thus, multiple representations play complementary roles with each other in illuminating and enhancing students' explanations (Authors, 2014a; Authors, 2014b; Yeo \& Gilbert, 2014). Considering that students' explanations are developed in the complementary relationships between different representations, it is essential to understand the features of each representation (Stieff, 2017).

Among various representations, student-generated drawing is a type of visual representation that supports the explanation of any type of content, whether structure, relationship or process. (Ainsworth \& Th Loizou, 2003; Quillin \& Thomas, 2015). Even though student-generated drawing represents ideas visually, it is constructed based on interacting with various modes of representation. For example, in making drawings, students can activate the referential links between verbal elements and nonverbal representations (Van Meter, Aleksic, Schwartz, \& Garner, 2006). Through this process, constructing scientific drawing can promote the formation of students' ideas by making the invisible visual and the complex simple (Quillin \& Thomas, 2015). In this context, student-generated drawings have been considered a pedagogical tool to form scientific explanations (Quillin \& Thomas, 2015; Van Meter et al., 2006).

Student-generated drawings are useful to foster scientific learning, especially for young children (Author, 2012; Brooks, 2009). Children's drawings have been perceived as an enjoyable tool for expressing their thoughts, feelings and opinions (Author 2012; Sozen \& Bolat, 2011). Considering that primary school students are not familiar with mathematical expressions, drawing can be an important teaching strategy in primary science learning. It is natural that student-generated drawing may not always be formal and established; this study 
noticed that student-generated drawing can be developmental in the learning processes with appropriate guidance (Brooks, 2009).

Until now, the main focus of existing studies on using student-generated drawing as a pedagogical tool has been examining the effects of student-generated drawings rather than investigating how to guide student-generated drawings. Several studies have researched the process of constructing students' diagrams, and some studies have dealt with the general process of constructing multiple representations including drawings (e.g., Tytler, Hubber, Prain \& Waldrip, 2013). Other researchers described the processes of constructing drawings (i.e. selecting, organising, integrating) that are not contextualised to the teaching and learning processes (e.g., Quillin \& Thomas, 2015). Despite a growing interest in student-generated drawing, relatively little attention has been paid to identifying ways of supporting students to draw.

How do students construct scientific drawings? How can we encourage students to make scientific drawings? For this, it is important to give students some directions on what is important and what criteria make their drawings scientific. Considering that making scientific drawings is one of important parts of students' scientific explanations (Yeo \& Gilbert, 2014), we need to encourage students to consider whether or not their ways of drawing are desirable for making scientific explanations.

In order to identify the ways to support student-generated drawing, this study was guided by a theoretical frame of 'norms' that appear when students construct drawings. Norms are shared patterns desirable in a community (Authors, 2016). Exploring norms formed in science classrooms can show what is considered important and desirable when students generate drawings in the classroom. Thus, we sought to identify the types and influences of norms that appeared in the drawing processes of gifted primary students in Australia. In particular, the desirable cases of norms formed in drawing can be a basis for 
establishing meaningful context for scientific drawing. The research questions are as follows: (1) what norms are formed in constructing student-generated drawing? and (2) how do these norms influence the construction of student-generated drawing?

\section{Theoretical backgrounds}

\section{The features of norms formed in educational practices}

Education aims to guide students in a way oriented to each academic discipline (Bruner, 1960). Norms, as a theoretical framework, have been studied in much educational research in order to explore behaviour patterns perceived as desirable in classrooms as well as aligning with the sociocultural practices of a community associated with the academic discipline (Driver, Newton \& Osborne, 2000; Yackel, Rasmussen \& King, 2000). For example, Yackel and Cobb (1996) argued that some specific ways of acting and interacting are shared in mathematics classrooms as normative criteria for arguing, explaining and justifying. Based on these ideas, they developed the notion of socio-mathematical norms, that is, 'normative aspects of mathematical discussions that are specific to students' mathematical activity (p. 1)' and investigated how the teacher and students constitute what counts as an acceptable mathematical explanation and justification as a norm.

Similarly, in science education, norms related to reasoning, justification or argumentation have been continuously studied (Authors, 2016; Becker et al., 2013; Driver et al., 2000; Lundqvist, Almqvist \& Östman, 2009). Lundqvist et al. (2009) defined norms in classrooms as 'rules for how to talk and act in a practice (p. 862)' and investigated two epistemological norms in making investigations or using scientific language. Becker et al. (2013) re-conceptualised the notion of socio-chemical norms in order to investigate disciplinary criteria for reasoning and justification. In this way, norms have been considered rules or criteria for acceptable ways of acting or talking in science classrooms. 
However, Authors (2016) pointed out that the term norm has been used along with similar concepts such as value and rule even though they have slightly different foci at different levels. Through a theoretical review, the meaning and attributes of norms were elaborated by comparing them with the similar concepts of 'value' or 'belief' and 'rule' (Horne, 2001). They argued that norms need to be differentiated from similar concepts such as values and rules in terms of three essential features: Justifiability, actions and sharing.

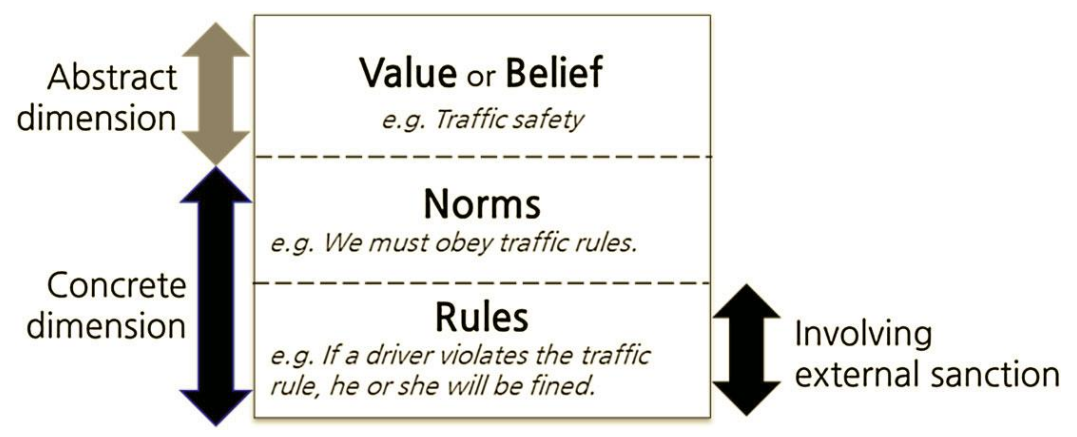

Figure 1. A comparison between norms and similar concepts (Authors, 2016)

First, norms are value oriented. Every norm involves its own justifiability based on the related value. For example, as shown in Figure 1, the norm of 'we must obey traffic rules.' is oriented to the value of 'traffic safety'. Second, however, norms entail concrete actions. As shown in the examples of Figure 1, norms show certain ways of acting; however, values remain abstract notions. Third, norms are shared among members. Rules can be also shared among members, however, they are usually enforced by external sanctions (Horne, 2001). Norms are followed with intrinsic value internally. If a rule set by the teacher does not obtain the students' willingness to engage in behaviour based on the rule, students may pretend to follow the rule in order to not get in trouble, but it is not their norm. In this vein, in Figure 1, the vertical axis represents the level of abstractness among the three concepts.

Every norm, then, emphasises something with its own justifiability and involves specific ways of acting that are shared among members (Authors, 2015). The essential 
features of norms found in previous studies were used as an analysis framework in this study. In order to investigate norms in classrooms, we established three essential questions based on these three features: (1) what are emphasised as norms (justifiability)? (2) how are the norms shared (sharing)? and (3) how do the norms act on students' behaviours (actions)? These three questions were used as criteria for extracting norms formed in science classrooms.

\section{The types of norms formed in educational practices}

In the existing studies in education, various types of norms were found in classrooms. Depending on their relevance to a specific area, the norms can be categorised into domainspecific norms and domain-general norms. The representative domain-specific norms include socio-mathematical norms in mathematics education (Yackel et al., 2000) and argumentation norms or socio-chemical norms in science education (Becker et al., 2013; Driver et al., 2000). For example, the norm of 'justifying reasoning using particulate level evidence' (Becker et al., 2013, p. 86) can be a domain-specific norm formed in the context of learning science. The domain here refers to science education or science classroom. In contrast, domain-general norms are the norms in general contexts. For instance, social norms have been reported as the norms that emphasise the order of utterances and equal opportunity in group participation (Authors, 2016). In this study, we focused on the norms that appear in making scientific drawings. Thus, the norms reported in this study are the domain-specific norms originating from discipline values or beliefs.

Depending on the agency of the formation, there are three kinds of norms: teacherinitiated norms, teacher-student-negotiated norms and student-initiated norms (Authors, 2016). Teacher-initiated norms are established by a teacher based on cognitive authority. Teacher-student-negotiated norms are suggested by a teacher, but are open to the possibility of various interpretations. Student-initiated norms are established by students. The desirable norms originating from values in science education are not established spontaneously by 
students, instead, they are established and encouraged by a teacher through concrete interventions (Authors, 2016). In this sense, the teacher's interventions or instructions can develop into norms as teacher-initiated norms if they satisfy the three essential features of norms in this study: justifiability, sharing and action. In other words, if the core ideas of the instructions are well shared and can change students' actions successfully in classrooms, these instructions can be norms. However, not every instruction can be a norm. If the core ideas of an instruction are not shared by students and the instruction fails to change students' actions, it cannot become a classroom norm but remains just a rule or direction.

\section{The process for constructing drawings: Meaning-making and representing}

In order to identify ways to support student-generated drawings, this study explored the features and influences of norms (our main focus) that appear in students' drawing processes (our main context). Drawing is the main context where norms are formed and a norm is a theoretical perspective used to explore ways to support student-generated drawings. In this section, we discuss the process for constructing drawings as a main context of this study.

To construct external representations, students need to think about the meaning and form of the representation (Bezemer \& Kress, 2008; Jewitt, Kress, Ogborn \& Tsatsarelis, 2001; Peirce, 1931-1958). When students draw phenomena, they need to make their own meanings about the phenomena and represent them in a visual form, thus the processes of constructing drawings can be interpreted as the integration of two representative processes: meaning-making and representing.

In the meaning-making process, students shape their own interpretation of the objects (Peirce, 1931-1958). Students create their ideas through multiple communicative means, such as verbal and visual modes of interaction (Jewitt et al., 2011). Therefore, to foster students' meaning-making, establishing a suitable multimodal environment is important. Meanwhile, in 
the representing process, students express the results of mediating between an object and the interpreting process (Peirce, 1931-1958). Because every mode of representation has its own forms or affordances (Bezemer \& Kress, 2008), each mode reflects different aspects of students' ideas (Kress, Jewitt, Ogborn, \& Tsatsarelis, 2001). Thus, we need to consider the strengths and weaknesses of each mode when using a specific mode of representation.

Another important point is that the two processes of meaning-making and representing have been brought together (Bezemer \& Kress, 2008; Peirce, 1931-1958). For example, in drawing processes, students represent their interpretations in drawings using visual representations (e.g., symbols) that have already reflected the students' ideas. That is, drawing processes repeatedly involve these two inseparable processes. In this sense, even though this study separately reports the features of each process, one process is inevitably reflected in the other process because the two processes are two sides of the same coin.

\section{Research method}

\section{Methodology}

A case study approach (Merriam, 1998) was used to address our research question of how norms are formed in a specific classroom environment and pedagogy that utilised studentgenerated drawings. The gifted classroom was considered a case to generate a "thick description" (Denzin, 2002) of the teacher's and students' routines and interactions within a

close and bounded system. The rationale for a case study approach was based on its research affordances to foreground the detailed actions that formed the basis of norms as well as provide a nuanced understanding within a bounded system consisting of the teachers' and students' cultural environment. By focusing on the contextual analysis of a classroom environment, case studies have the opportunity to add more in-depth information to what is known from previous research (e.g., Driver et al., 2000). 


\section{The participants}

This study sought to explore the features and influences of norms in constructing students' drawings. Since primary students have difficulty visualising abstract concepts or ideas, a productive place to begin is by exploring desirable ways to guide student-generated drawing using specific cases. Thus, we selected gifted students because they tend to have higher than average confidence and enthusiasm for learning science. This study was conducted in a primary gifted and talented program in Australia. The participants were 15 students who were selected for this program from local primary schools, their teacher in a physics class and the researchers.

The participating students were 11 to 12 years old in Years 5 and 6 . The 15 students consisted of four groups of three or four students. The students chose physics lessons voluntarily among various subjects offered in the gifted program, which suggested that they had higher interests in learning physics than an average primary school student.

Teacher K had taught the primary gifted students for 11 years of his 30 -year career as a teacher. The teacher was in charge of the physics lessons in the gifted program. He had a great deal of experience with primary gifted students and was perceptive in understanding their answers and guiding them.

The three researchers participated in the lessons as assistant teachers. Specifically, the first, second and third authors of this study assisted teacher $\mathrm{K}$ in his teaching practices. All of them had doctoral degrees in science education. The first and second authors were researchers as well as 10-year experienced primary school teachers. The third author was an associate professor in science education at a nearby university. In our theoretical framing, norms are defined as "specific ways of acting that are shared among members (p. 5)", and the researchers were also part of this shared community. The teacher and the three researchers 
intervened together in the students' drawing processes as participating members in the classroom.

\section{Data collection}

In collecting data, the three researchers and Teacher K continuously discussed how to establish lesson topics, teaching materials, questions and feedback when they organised, practiced and evaluated lessons. A cycle of organising, practicing and evaluating lessons was repeated in the whole process of gathering data through formal and informal meetings before and after each class (See Figure 2). Throughout the process, the researchers did not ask the teacher to establish any specific norms nor mention the term "norms" to the teacher. Even the researchers themselves also did not know what kinds of norms were being formed. Only when we designed, practiced and evaluated the lessons did we reflect on what we considered as important in scientific drawings that could support the explanation of phenomena. In this sense, the norms reported here were not intentionally established as a priori; rather, they were found or investigated based on instructions that occurred naturally in the science classroom.

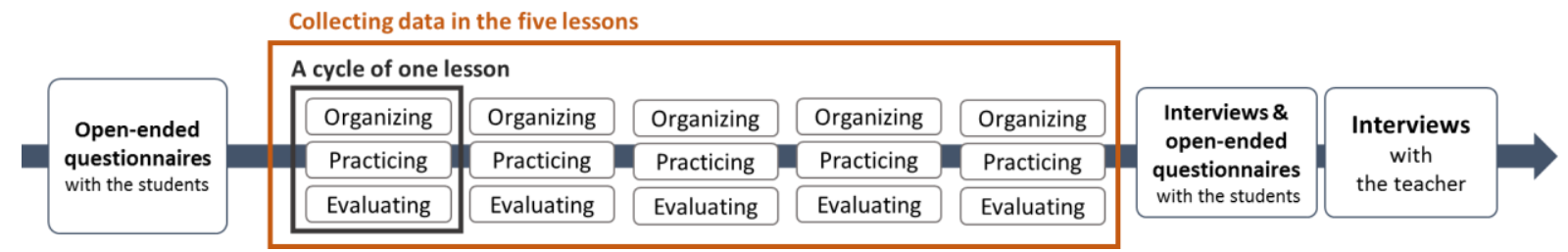

Figure 2. Procedure for collecting data in this study

When organising lessons for this study, each lesson was designed using the Thinking Frames Approach (TFA) to facilitate students' drawing (Newberry \& Gilbert, 2007). The TFA consists of six steps. In the early two steps of 'setting the question' and 'brainstorm', through hands-on activities and discussions, students had opportunities to generate their ideas verbally. Then, in the third step, 'see/visualise', students visualised their thoughts in drawings. In the final phases, students produced paragraphs and evaluated their explanations. 
The lesson topics mainly focused on properties of matter and thermal phenomena. These topics deal with phenomena that primary school students can easily experience in their everyday lives (Na \& Song, 2014), and this can help them to generate their own ideas. In each topic, we established the main questions for students to draw as shown in Table .

Table 1. Lesson topics and main questions of five lessons

\begin{tabular}{l|l|l}
\hline Lesson & Topics & Main questions for drawings \\
\hline 1 & States of Matter & $\begin{array}{l}\text { If we tilt three bottles containing solids, liquids and gases } \\
\text { respectively, what happens in each bottle in terms of particles? }\end{array}$ \\
\hline 2 & $\begin{array}{l}\text { Water } \\
\text { Pressure }\end{array}$ & $\begin{array}{l}\text { How are the ways of jets of water different depending on the size } \\
\text { of bottles and the water depth? Why? }\end{array}$ \\
\hline 3 & $\begin{array}{l}\text { Air } \\
\text { Pressure }\end{array}$ & $\begin{array}{l}\text { What happened in the cylinder when the air of a container is } \\
\text { decompressed? Why did it happen? }\end{array}$ \\
\hline 5 & $\begin{array}{l}\text { Changes of } \\
\text { Air Pressure }\end{array}$ & $\begin{array}{l}\text { What happened to the egg and the air inside / outside of the } \\
\text { bottle? Why? }\end{array}$ \\
\hline
\end{tabular}

Five physics lessons were implemented in the classroom each week over the course of five weeks. The participating students attended one two-hour lesson with one topic per week. During the lessons, various data were collected through video and audio records of lessons, observation notes, interview records with class members and students' worksheets.

In order to evaluate the lessons, we had regular post-lesson meetings to check the level of activities, the appropriateness of questions, the students' responses and how to give feedback to students. In lesson planning and evaluating, specifically, the teacher and the researchers discussed the main questions that the teachers asked to the students' drawings or feedback they gave to students about their drawings. These processes can easily show the ideas which were emphasised to students about their drawings, which can contribute to 
forming the norms. From these meetings, we reflected on what had been discussed in order to apply it to the next lesson. The meeting records and notes were also collected as data.

In addition, before and after the five lessons, open-ended questionnaires and interviews were performed as well. The questionnaires and interviews consisted of the questions dealing mainly with the features of good scientific drawings and the processes of constructing them. The pre/post-questionnaires and post-interviews were complementary data to check the influence of the norms by investigating the participants' perceptions on their drawings.

\section{Data analysis}

In order to investigate the types and influences of norms, we analysed data in four steps. In the first step, the video data were partitioned into discrete episode according to the participants' interactions and activities (Erickson, 1992), such as having a class/group discussion, doing experiments and drawing. For example, in a class discussion before an experiment, episodes were determined by the boundaries of shifting interactions (e.g., explaining to students how to set up the experimental equipment, predicting what will happen in the experiment and why) of each activity.

Second, in each episode, each utterance was coded as meaning-making or representing process depending on the focus of participants' actions. That is, in each episode, we determined whether the focus of participants' actions was on meaning-making or representing. The actions revolving around how to interpret phenomena (e.g., talking about why a phenomenon happens) were determined as meaning-making processes, while the actions around how to represent (e.g., talking about how to show) were determined as representing processes. For example, the actions shown in Table 2 were determined as a meaning-making process because the main focus of the actions was on how to interpret three states of matters. 
Table 2. A sample of an analysis

\begin{tabular}{l|l|l}
\hline Episode (Lesson 1: States of matters, Group4 1:26:10) & Drawing processes & $\begin{array}{l}\text { Emphasised } \\
\text { words }\end{array}$ \\
\hline R3: In the liquid, why does it change its shape? But why & Meaning-making & Explain why \\
the solid doesn't change its shape? Could you draw the \\
diagrams to explain why?
\end{tabular}

For the next step, to extract the norms, the researchers checked the emphasised or frequent ideas that emerged in meaning-making and representing processes using a constant comparative method (Merriam, 1998). These ideas were then separated into categories by how similar they were in their meanings. For example, in Table, the emphasised ideas of 'show why', 'why it happens', 'how do you explain' and 'explain why' were extracted into the category of 'explaining why'.

In particular, in the process of inductive categorical analysis (Glaser \& Strauss, 1967), the emphasised ideas were checked based on three essential features of norms mentioned in the theoretical background. That is, the ideas were extracted as norms when they were shared as desirable ways to help students draw in a specific way. If the core idea of the behaviour failed to be shared by students or did not change students' actions, it would not be recognised as a norm and would be treated as just a behaviour.

Finally, in order to identify the influences of each norm more clearly, we analysed the norms and their related data back and forth. In constantly reviewing processes, it was found 
that a total of six norms influence drawings by connecting to each other. For example, in the following interview, G4S3 answered that he drew particles to explain why.

Interview (G4S3, 00:11:57)

$\mathrm{R}$ : What do you think are the strengths of drawing particles?

G4S3: It shows what the molecules are doing at that time, so it could help explain why it happens...

In addition, in Table, the researchers encouraged students to 'think in terms of particles' to 'explain why'. Thus, the norm of 'thinking in terms of particles' was recategorised as a sub-norm for 'explaining why' and this norm and sub-norm influenced students' drawing together (refer to Figure 3).

Through these steps, we were able to figure out the types of norms and their influences on drawing processes. By repeatedly checking through peer review and multiple sources of data, the researchers were able to characterise the elaborated features and influences of the norms.

\section{Results}

In this section, focusing on the meaning-making and representing processes, the features of two main norms and four sub-norms are presented (Figure 3). The norms found in this study are domain-specific norms because they relate to the construction of scientific drawings. Considering that scientific drawings are generated as part of the process of constructing scientific knowledge, the norms found in this study can be regarded as epistemic norms. Specifically, the epistemic norms reported in this study have both cognitive and social aspects because the process of constructing scientific drawings was affected by students' cognitive understanding and social interaction (Duschl, 2008). Meanwhile, in terms of the subject of the formation, the norms reported here are teacher-initiated norms as well that are formed by teacher guidance in pointing out desirable ways to draw in classrooms. The rules or 
instructions set by the teacher may or may not develop into the norms in the classroom. In this study, the three essential features of norms, justifiability, sharing and action, were used as criteria for distinguishing between rules and norms. Therefore, the types and the influences of each norm in Figure 3 are described in terms of the three essential features of norms: what are emphasised as norms, how the norms are shared and how the norms act on students' drawings.

\begin{tabular}{|c|c|}
\hline $\begin{array}{l}\text { Norms in meaning-making processes (NM): } \\
\text { Explaining why }\end{array}$ & $\begin{array}{l}\text { Norms in representing processes (NR): } \\
\text { Telling a story visually }\end{array}$ \\
\hline $\begin{array}{l}\text { (Sub-norm NM1) Associating with key } \\
\text { factors and their relationships }\end{array}$ & $\begin{array}{l}\text { (Sub-norm NR1) Symbolizing with the most } \\
\text { suitable key }\end{array}$ \\
\hline $\begin{array}{l}\text { (Sub-norm NM2) Thinking in terms of } \\
\text { particles }\end{array}$ & $\begin{array}{l}\text { (Sub-norm NR2) Representing the meaning } \\
\text { easy to understand }\end{array}$ \\
\hline
\end{tabular}

Figure 3. Key finding: The norms formed in constructing student-generated drawings

\section{Norms in meaning-making processes (NM)}

\section{'Do you think this drawing can explain "why”?': Explaining why}

Scientific drawings can show various mechanisms involved in phenomena, such as structures, processes and relationships (Quillin \& Thomas, 2015). In particular, in constructing explanatory drawings, it is essential to encourage students to show not only the phenomenon itself but also the mechanisms involved in the phenomenon. Thus, we observed in every lesson that Teacher $\mathrm{K}$ frequently asked students to discuss not only what was happening but also why it was happening. The following excerpt shows the questions which the teacher asked the students after the experiment:

Excerpt 1 (Lesson 4: Changes of air pressure, classroom discussions 1:24:25)

T: Who observed what happens?

G2S4: It [the egg] broke but it got in the hot glass because the glass is hot... 
T: Who can give an explanation as to what happens? G2S4 tried to... almost said what he observed, we need someone's telling why?

In the above classroom discussion, the teacher asked students to explain why something happened in addition to asking what happened. In the following interview, Teacher K mentioned that it is important for students to tell their own stories about experiments that include both what happens and why it happens:

Excerpt 2 (Interview with Teacher K 00:16:10)

R1: Do you have any good questioning to encourage their drawings?

T: I think a good questioning technique is to say to them... what stories you are telling. You should be telling a story of the experiment in drawings...

R1: What is the meaning of 'telling a story' you mentioned?

T: $\quad$ Well... like telling a story of an experiment... Telling a story means recounting what happens and why in the experiment.

The act of 'telling a story' that the teacher mentioned in Excerpt 2 can be interpreted as a meaning-making process from Peirce's model. That is, in constructing their drawings, students were encouraged to make their own meanings about the phenomena that can explain what happened and why it happened.

However, we observed that at first the students were not familiar with explaining the reasons for the occurrence of the phenomena in their drawings, as illustrated in the next excerpt:

Excerpt 3 (Lesson 1: States of matters, Group 4 1:25:53)

R3: [Looking at Figure 4] Can I ask you how would you use your diagrams to answer the questions?

G4S4: Uh... It shows what happens.

R3: Yeah, it shows what happens but it doesn't show why it happens. Do you think this drawing can show why it happens? 
G4S4: I don't think it does...

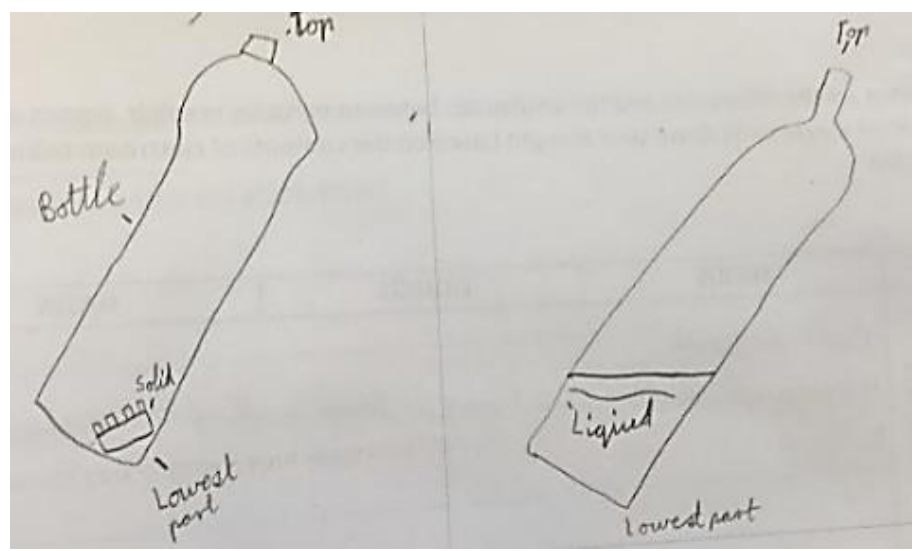

Figure 4. The first diagrams of G4S4

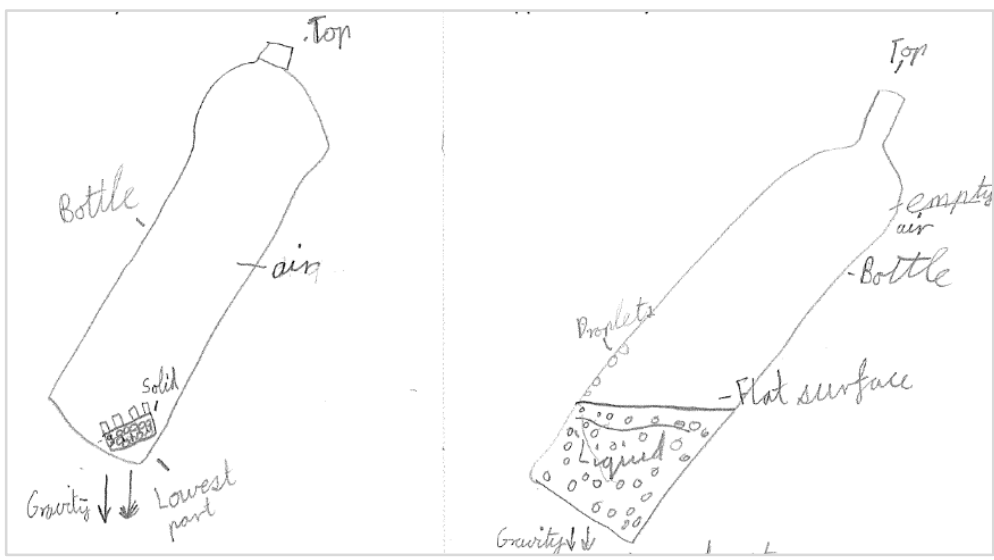

Figure 5. The final diagrams of G4S4

In the above excerpt from Lesson 1, G4S4 finished his diagrams very quickly because he only drew the results of the experiment (Figure 4). The researcher then asked the student to draw 'why it happens', so the student modified his drawings (Figure 5). In his drawing, G4S4 tried to explain 'why it had happened' by drawing the particles and the related concepts. In this way, the norm emphasising that 'scientific drawings should explain why' was shared in the classroom discussions.

Similarly, in various ways, students were asked to construct their own interpretations in their drawings. For example, the norm of 'explaining why' appeared in using an evaluation rubric or giving feedback. In the evaluation rubric the students used (Figure 6), 'explaining 
why it happened' was an important criterion for judging the levels of the drawings. In addition, students received feedback to encourage them to explain why in their drawings. In these ways, the norms were shared with students.

Emphasising 'why' by using an evaluation rubric
\begin{tabular}{|l|l|}
\hline - Level 1: & $\begin{array}{l}\text { Simple drawing of the equipment } \\
\text { - Level 2: }\end{array}$ \\
- Level 3: & $\begin{array}{l}\text { happening } \\
\text { Drawings to show what I saw happening } \\
\text { with some drawing that explained why it } \\
\text { happened }\end{array}$ \\
\hline
\end{tabular}

\section{Emphasising 'why' by giving feedbacks}

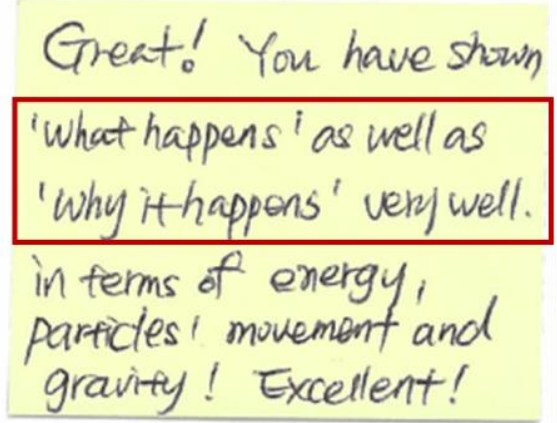

Figure 6. Emphasising 'explaining why' through rubrics and feedback

The norms influenced students' perceptions of what scientific drawings are and how to construct them. The following excerpt shows some of the students' responses from the post open-ended questionnaire on the question about good scientific drawings:

Excerpt 4 (Questionnaire: What do you think are good scientific drawings?)

G1S3: I think drawings that are good are drawings that shown in as much detail why and how it has happened but they are also easy to understand.

G1S2: Good scientific drawings should include cause and effect.

Similar to the examples in Excerpt 4, more than half of the participating students considered 'explaining why' to be one of the features of good scientific drawings.

In addition, the norms influenced students' drawings directly. As time went by, we observed that students came up with and used their own ways of explaining why. For example, G4S4 added arrows to show the effect of gravity because he thought that gravity affects the position of solids and liquids in bottles (Figure 5). He also drew many circles to show the particles' movements because the movements of particles influence the shapes and volumes of different types of matter. In this way, to construct invisible mechanisms, students 
started drawing particles and representing other main concepts (e.g., gravity), which developed the following related sub-norms.

\section{(Sub-norm NM1)}

'What concepts need to be dealt with?': Associating with key factors and their relationships

The process of constructing ideas entails selecting and organising some key information from presented materials (Mayer, 1996), which is the same as the process of constructing drawings (Quillin \& Thomas, 2015). In this context, to encourage students to construct their own stories in drawings, it is important for students to select main concepts and organise their relationships properly. For example, in the following excerpt, the students were guided to select key concepts and re-organise their relationships in order to explain why three states of matter have different features.

Excerpt 5 (Lesson 1: States of matter, classroom discussions before drawings 1:16:55)

T: What can be keywords in this experiment?

Ss: Movement! Particles! Liquids!

T: What about the actual movement of the particles?

G1S1: Uh.... Like... Break?

T: $\quad$ Break? So, the 'bond' of the particles was breaking?

G1S1: Yeah, kind of.

T: $\quad$ But it is a kind of another word you can say... bond.

G1S1: Oh, it is because like the waters left here.

In Excerpt 5, the teacher was trying to make connections among key concepts such as movement and particles. First, students suggested movement, particles and liquids as keywords; however, the teacher tried to develop their ideas in terms of 'the movements of particles'. When G1S1 mentioned 'break', the teacher connected 'breaking' with the related key concept of 'bonds of particles'. Teacher K thought that his questions should be designed 
to help the students develop key ideas, including the main concepts. The following excerpt shows his opinion about good questioning.

Excerpt 6 (Interview with Teacher K 00:19:00)

T: $\quad$ Before they drew their drawings, we can ask them what key ideas should appear in your drawings. You can take from them some keywords, and say what key ideas should appear.

In every lesson, by asking questions and looking at the students' worksheets, students were encouraged to think about some keywords and organise their relationships. On the students' worksheets, the section for selecting keywords was set before starting drawing (the blue box in Figure 7). Even while constructing their drawings, students were asked to rethink their drawings focusing on the keywords. In the following example, R1 talked about the meanings of the student's drawings with the keywords.

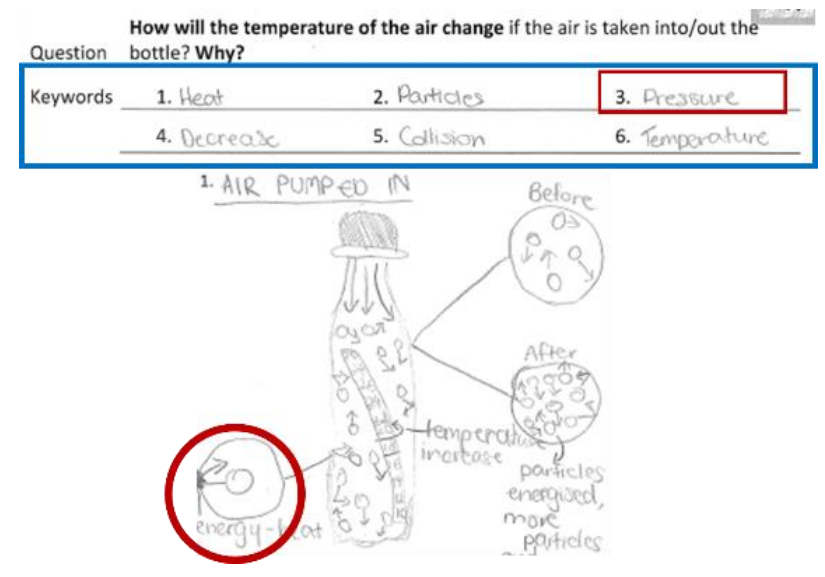

Figure 7. G2S2's drawings in Lesson 5

Excerpt 7 (Lesson 5: Changes of air temperature, group 2 01:30:55)

[As shown in the red box in Figure 7, 'pressure' was selected as one of the keywords]

R1: In your keywords, heat, particles and pressure were selected. I can see heat and particles in your drawings but where is the pressure? How did you visualise pressure?

G2S2: [pointing the red circle in Error! Reference source not found.] The particles are colliding to wall, which causes pressure. 
In this way, the norm of associating with key factors (NM1) was formed through the teacher's questioning, the worksheet and individual interactions. As a result, we observed that students considered it important to express the main concepts in their drawings. When we asked students to explain the important parts of their drawings, half of them (15 out of 30 answers) mentioned key concepts in each lesson in ways similar to those in Excerpt 8 below.

Excerpt 8 (Worksheet: What are the important parts in your drawings of today's experiment?)

G4S3: The important part was the air pressure and the particles of the outer container and inner container. (Lesson 3: Air pressure)

G1S2: In my drawings, it is important to visualise that why the gas particles did and what was the effect in relation to the cold and hot (Lesson 4: Changes of air pressure)

G4S4: Pressure, Speed, Heat (Lesson 5: Changes of air temperature)

In addition, students thought that using keywords can contribute to constructing explanations. In the following interviews, G2S1 said that he used keywords to make the complete explanation (Excerpt 9), and G2S2 explained that thinking about what keywords did as well as what they caused was her strategy to showing why (Excerpt 10).

Excerpt 9 (Interview with G2S1 00:03:15)

R4: So, how did you select the keywords?

G2S1: I selected them ... I just used words to make the whole things... (keywords) come to what's the main things in the experiment...

Excerpt 10 (Interview with G2S2 00:06:56)

R1: $\quad$ So do you have your own ways to show 'why'?

G2S2: Oh... whatever... what the keywords are doing, and then that is what causes.

These responses show that the sub-norm of 'associating with keywords' influenced the construction of students' drawings with its main norm of 'explaining why' together. Furthermore, from a multimodal perspective, selecting and organising the keywords 
represented in the verbal mode is crucial to constructing effective student-generated drawings in the visual mode. As shown in Figure 7 and Excerpt 7, the pictorial representations of the particles colliding with the wall and the verbal discussions and labels related to the keywords complement each other in developing the student's complete explanation. In this case, a pictorial representation can compose a deeper meaning in combination with the other modes of representation. The norm of 'associating with key words' can promote the complementary relationships between pictorial and verbal representations in constructing student-generated drawings.

(Sub-norm NM2)

\section{'Did you guys think in terms of particles?': Thinking in terms of particles}

To answer 'why' questions related to thermal concepts, it is essential to interpret the presented phenomena at the particle level. Thinking about phenomena in terms of particles can give students some important cues to explain 'why'; thus, it had been continuously emphasised during the lessons. For example, the following excerpt shows that R3 encouraged students to think about particles' movements in order to answer the questions.

Excerpt 11 (Lesson 1: States of matters, group 4 01:28:40)

R3: Could you draw the diagrams to explain why?

G4S1: I thought... because... The liquids... it's on a sort of angles... [tilting the water bottle] Soda takes up space...

R3: What do you need to draw in order to explain why? How about going back to this question? Did you guys think in terms of particles? Visualise it in your minds. How do you explain the solids have definite shape and volume in terms of particles?

G4S4: The solid seems to be easy... it's just 'cause they are connecting, so...

R3: So, how would you draw it? [G4S4 started to draw the particles in his drawings.]

In Excerpt 11, R3 emphasised thinking the particles' movements in solids, liquids and gases because it could help students explain the different shapes and volumes of each state. 
For the same reason, in the student worksheets, the researchers put a note saying 'You can draw the whole thing or 'zoom in' on smaller sections.' in order to help students to draw at a particle level.

However, thinking in terms of particles was not easy for these primary students. In the following interview, G4S2 mentioned that thinking how molecules move was difficult. G4S2 explained that he dealt with this difficulty by trying to 'picture it in my head.'

Excerpt 12 (Interview with G4S2 00:02:23)

R4: So, related to this, what was some of difficulties in making these drawings?

G4S2: Definitely, we've been seeing it was picturing how to molecules are moving...

R4: Right. So how do you deal with these difficulties?

G4S2: Well. I did... some sorts of... like trying to picture it in my head, and used which way of the movement to show how they move...

At first, students were not familiar with thinking about and drawing particles. They did not think about particles and how to visualise them as shown in Excerpt 11; thus, they were guided to visualise at a particle level in their minds. Similarly, in Figure 8, G3S3 also did not draw particles at all and just showed what happened. Thus, G3S3 got feedback (as shown on the attached note in Figure 8) that emphasised the particle perspective.

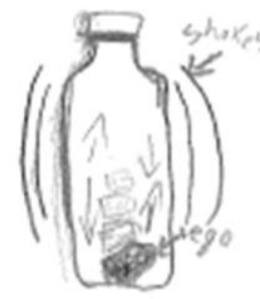

Solids

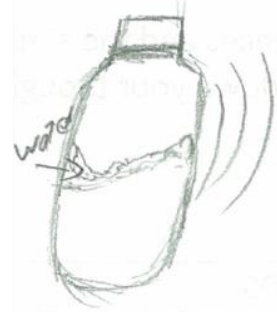

Liquids

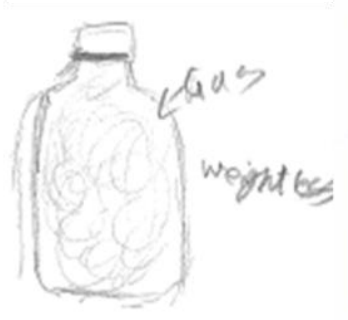

Gases
Ican see "What happins"

in your drawing, but

I want to see "Why"

in terms of particles.

Figure 8. G3S3's drawings in Lesson 1 and their feedback 
In this way, the norm of thinking in terms of particles (NM2) was shared in various ways, such as individual interactions (Excerpt 11), the notes presented in worksheet and, sometimes, feedback about students' drawings (Figure 8). In particular, by thinking from the particle perspective, students can get some important cues to explain phenomena, as shown in Excerpt 11. In other words, because students had repeated experiences interpreting other concepts such as pressure or states of matters in terms of particles, the norm could gradually be shared with students.

The norm of NM2 also influenced both the students' drawings and their perceptions of scientific drawings. With continuous emphasis, students became familiar with how to think about particles and how to use zoom-in or close-up shots. Thus, as the lessons progressed, students became better in considering more detailed factors related to particles such as the distances among particles (Figure 9) and their directions or speed (Figure 10).
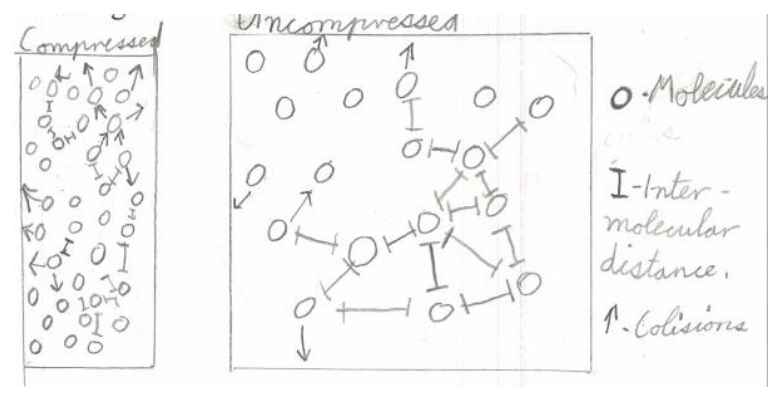

Figure 9. G4S4's drawings in Lesson 3 (air pressure)
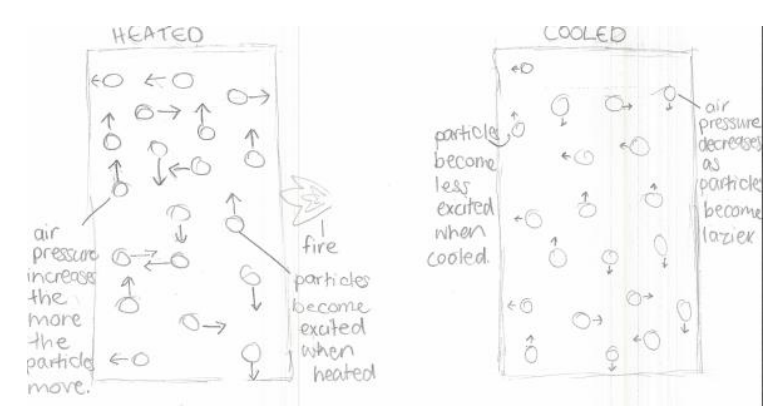

Figure 10. G2S2's drawings in Lesson 4 (changes of air pressure) 
Furthermore, the participant students also understood the values of particulate explanations. In the following interviews, students responded to the question about the strengths of drawing particles.

Excerpt 13 (Interviews with G1S2, G4S3)

G1S2: We need them to show the persons are seeing it more details. ... you can't see particles... if you wanna draw particles, you have to draw close-up to make it more visible to the reader. [00:14:49]

G4S3: Well... the particles are the part of matter which everything is made of. And it is important to show where particles are and what they doing in order to prove your point. [00:44:14]

In the above interviews, students recognised that drawing particles can help answer 'why' in a variety of ways. First, students argued that the particles' states or movement can show invisible processes related to phenomena, thus drawings are useful in explaining the details of what is going on. Second, and more fundamentally, G4S3 explained that particles are what everything is made of, so it is important to draw them in order to explain 'why'. These responses indicate that the norm of NM2 influenced students' ideas.

\section{Norms in Representing process (NR)}

\section{'Can you visualise your ideas?': Telling a story visually}

Drawings show ideas in 'visual ways' (Ainsworth, Prain, \& Tytler, 2011). Naturally, in the representing process of drawings, students were called on to show their ideas visually. Thus, the teacher and the researchers tried to encouraged students to visualise their thoughts. We observed that students were often given feedback such as 'You did explain well. But can you visualise it?' (R3, Lesson 3) and 'Please do not use too many words in your drawings'

(Teacher K, Lesson 2). However, this does not mean that the visual representation alone can constitute an entire scientific explanation. We attempted to provide students with opportunities to visualise their ideas as one aspect of the pedagogical processes in student- 
generated drawing. In this context, students who explained their ideas only in words also received some feedback to emphasise picturing what they meant (Figure 11).
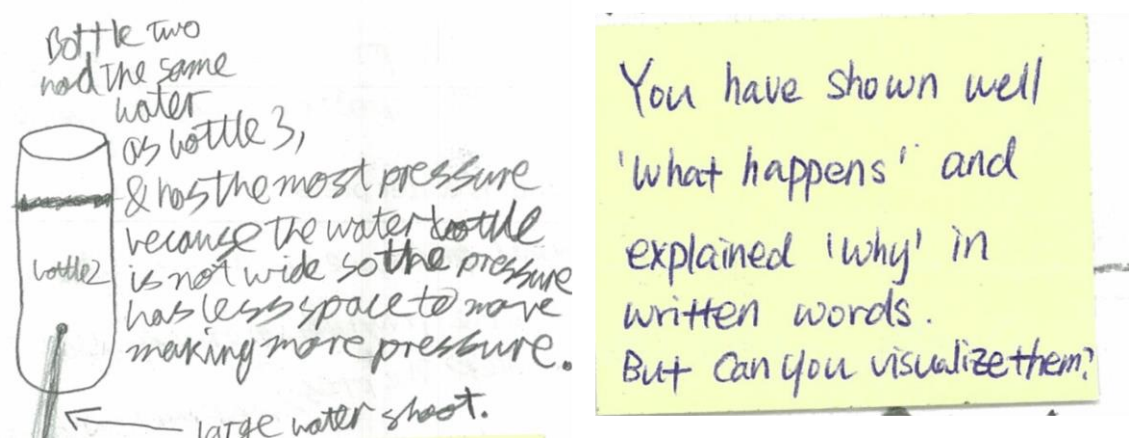

Figure 11. G3S3's drawing in Lesson 2 (water pressure) and its feedback

It was especially interesting that every representing process occurred in parallel with the process of meaning-making. In other words, at every meaning-making moment, students were also asked how to visualise what they meant. For example, in the last sentence of Excerpt 11, R3 asked students 'So, how would you draw it?' right after discussing how the solids' particles connected to each other. The response shows that the two processes of constructing meanings and visualising them are not linear but instead occurred together interactively and repeatedly in the process of drawing. In this study, the meaning and form of each representation were considered together in producing representations (Bezemer \& Kress, 2008); thus, the meaning-making and representing processes occurred together. How to visualise drawings is always developed with connections to how to make meaning.

However, representing visually was difficult for these primary students. The following interviews show their difficulties.

Excerpt 14 (Interview with G4S2, G4S1)

G4S2: When I draw something, I'm not sure exactly how to draw it because I'm still developing them in my mind.

G4S1: And sometimes it is a little bit hard, like ... come up ways of showing force or pressure, molecules, particles. 
R3: There are what we cannot see, so it is hard to make some...

G4S2: Imagine them.

Excerpt 15 (Interview with G1S3, G1S2)

G1S3: Expressing everything that you want to express on a piece of paper... It's just too hard.

G1S2: Uh... in this experiment... the egg on the bottle, I had difficulties in explaining what was happening exactly without many words...

As shown in the above interviews, students had difficulties visualising their thoughts for many reasons. First, in Excerpt 14, G4S2 had some difficulty when he visualised ideas that he had not developed enough. This shows that students' ideas can sometimes develop continuously while they draw. Second, G4S1 mentioned his difficulties in visualising the concepts of pressure and force. The process of representing concepts externally is adifferent matter than-from understanding them internally (Van Meter \& Garner, 2005). Therefore, even if students understand concepts well, representing them may not be easy. Furthermore, because most science concepts are abstract and invisible, students said that they struggled to imagine how they looked and how they moved. Third, in Excerpt 15, G1S2 and G1S3 talked about the difficulties of visualising a detailed process. To explain why, students should visualise the complex mechanisms involved in phenomena. That is why G1S2 usually used many words in his drawings instead of visualising the process.

Despite the above challenges, we observed that students found their own ways to visualise abstract or complicated phenomena. For example, in Figure 12, the complicated processes were separated into smaller steps and visualised step by step. In Excerpt 16, students answered that using many keys and legends to symbolise concepts is helpful in explaining detailed things. 


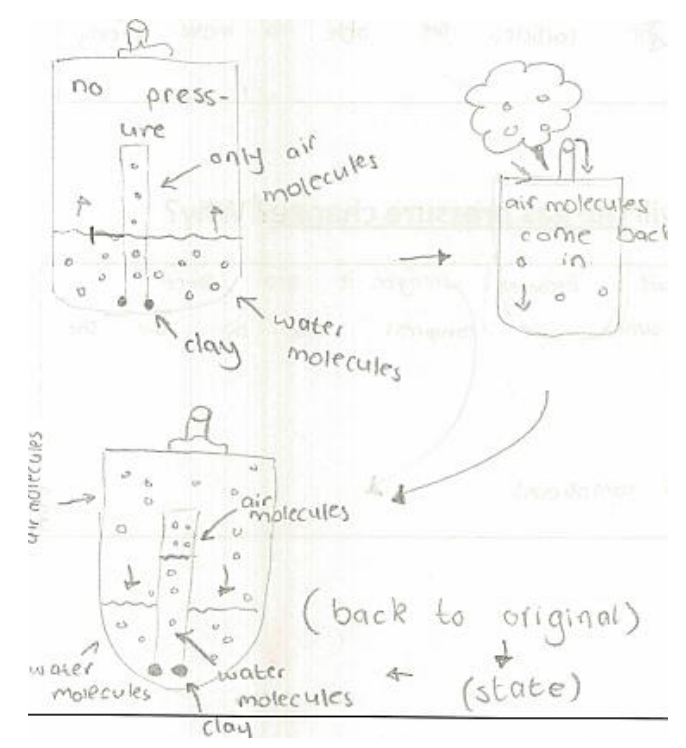

Figure 12. G1S1's drawings in Lesson 3 (air pressure)

Excerpt 16 (Interview with G1S3, G1S2: continuing to Excerpt 15)

R1: So, how did you deal with this difficulty?

G1S3: I just tried to use many keys as possible...

R1: Using keys is helpful to show some detailed things?

G1S2: Because, keys and legends, they represent words like vibration and collisions...

In these ways, students found their own ways to visualise what they wanted to express. These ways were shown in the following two sub-norms. The first involves symbolising abstract concepts or invisible processes, while the second is related to how to represent them in ways that are easy to understand.

\section{(Sub-norm: NRl)}

'Every symbol has its own meaning, but you should select what is more appropriate.': Symbolising with the most suitable key

To visualise complicated processes, we observed that students symbolised abstract concepts using keys. It was especially interesting that students used different symbols even though they represented the same phenomenon. For example, in the lesson about states of matter, students expressed the movement of gas particles with different symbols as shown in Figure 13, Figure 14, and the excerpts below. 


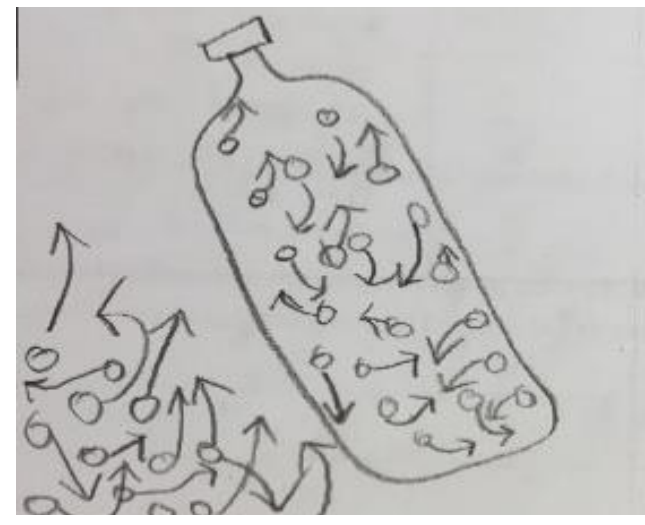

Figure 13. Symbols of gas particles' movements (G4S2)

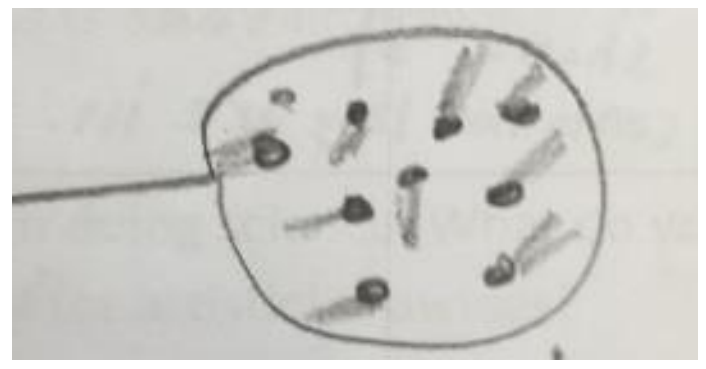

Figure 14. Symbols of gas particles' movements (G1S2)

Excerpt 17 (Lesson 1: States of matter, group 1 1:37:53)

R1: Can I ask the meaning of this tale of the particles?

G1S2: That's just like the movement. I would like to show its energy.

R1: Oh, it's a good idea. Where do you get this idea from?

G1S2: Because gas particles move so fast. It's like a shadow of a particle following after it.

Excerpt 18 (Lesson 1: States of matter, group 4 1:48:14)

R1: What do these arrows mean?

G4S2: The gases are floating around freely, so they can go ... The gas can spread out everywhere and they got lots of space.

In the above examples, students symbolised gas particles with different keys depending on their explanations. G4S2 used the arrows visualising the directions of particles' movements to explain the indefinite shape and volume of gases, while G1S2 used the 
shadows visualising the fast movement of gas particles to explain the gases' energy. A sign is not only an outcome of interpretation but also a basic element representing an object for its further interpretation (Peirce, 1931-1958). In the above examples, the arrows and shadows had their own meanings to different students, such as direction and speed; however, at the same time, they also further support each student to develop different explanations such as volume and energy of gases. That is, each symbol with different meanings also influences the continuously developing explanations by a particular student.

When creating and using their own keys, it was emphasised that students should choose the symbols that would be most suitable for showing their interpretations well. For example, in Excerpt 19, R1 mentioned the importance of symbolisation using the most suitable key.

Excerpt 19 (Lesson 2: water pressure, classroom discussion)

[Students explained which symbols they used and why they chose their symbols.]

R1: Okay.... I think there is no correct answer ... But we need to think about what we want to more focus on. Each symbol has its own values to show the specific aspect of phenomena but you should select what is more appropriate to show your explanations.

In Excerpt 19, how to select symbols meaningfully in scientific drawings was discussed. R1 emphasised considering which symbol can best show the students' explanations. In the same context, students had various chances to rethink each symbol's meaning and value. For example, the teacher and the researchers often asked students 'what does this key mean?' in order to clarify and rethink the meaning of the keys.

Through these processes, students started to perceive how to generate symbols depending on their purposes and the importance of using symbols in ways that best support their meanings. 
R4: Can you explain how you decided to use these symbols?

G4S4: I decided to use this symbol... this blank circle for the particle, like molecule, instead of drawing one oxygen atom, two hydrogen atoms...

R4: How did you get the idea to draw circles for molecules?

G4S4: I just think drawing all individual atoms in the molecules would be practical for diagrams, but that [drawing all atoms] doesn't really matter about that... So, it [the blank circle] is easier to get the meaning of the diagram.

In the above interview, G4S4 answered why he did not represent every atom. He explained that drawing atoms was not related to the main question; furthermore, omitting atoms made it easier to 'get the meaning' of his diagrams. That is, the norm of symbolising with the proper keys (NR1) influenced the students' practices of why and how they symbolised phenomena in drawing.

(Sub-norm: NR2)

'In a way that is easy for readers to understand?': Representing the meaning easy to understand

Drawing is a sociocultural practice (Prain \& Tytler, 2013). When students make drawings, they interact with an object itself, their experience or ideas about the object as well as others who will see their drawings (Ainsworth et al., 2011). Thus, in the lessons, an emphasis was placed on representing ideas in ways that others will find easy to understand.

How can we visualise drawings in ways that are easy to understand? This was a challenge for these primary students. First, in many cases, students made inconsistencies in their drawings between what they knew and what they drew. For instance, in Figure 15, it is hard to recognise the differences between liquid and gas particles. 


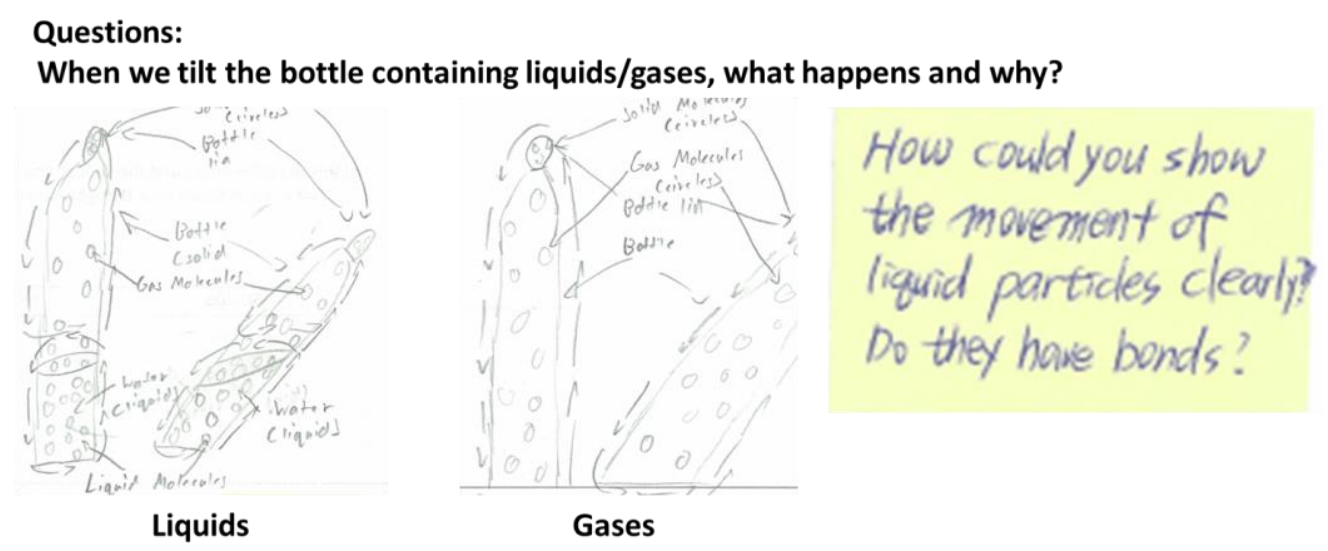

Figure 15. G4S1's drawings in Lesson 1 (states of matters) and their feedback

However, in his worksheet, G4S1 explained that 'liquid's particles are tightly packed but they move around each other. Gas particles are loosely packed and the particles move around freely'. He accurately knew the differences between the particles' movements in liquids and gases but could not visualise them properly. Thus, in the feedback for Figure 15, G4S1 was asked to clearly show the movements of the particles and the bonds among particles.

Second, using symbols consistently as well as clearly is another difficulty in representing. We observed that students did not often describe the meanings of keys in legends and used the same symbol for different meanings (Figure 16). Thus, through the feedback shown in Figure 16, students were continuously encouraged to use their keys consistently and clearly.

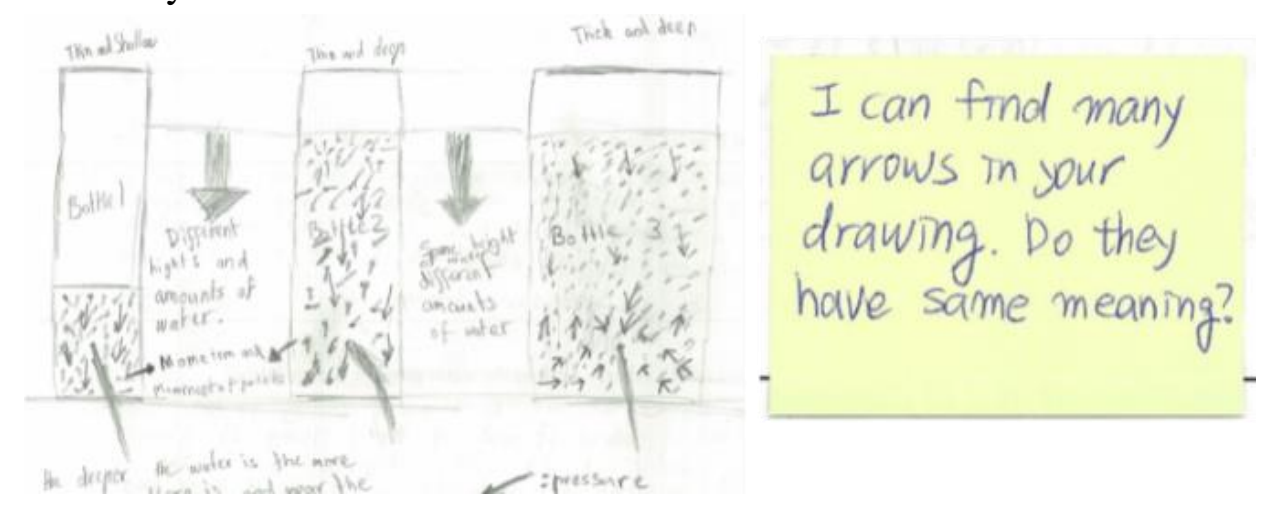

Figure 16. G4S1's drawings in Lesson 2 (water pressure) and their feedback 
The norm of representing the meaning in easy to understand ways (NR2) was also shared through various channels, such as individual interactions and evaluation rubrics that introduced desirable ways to visualise. For example, how to use symbols was presented as one of the criteria in the rubric for self-evaluations. The rubric emphasised that using symbols consistently in ways that make sense to others. Similarly, in every lesson, students were asked 'what does this symbol mean?' Through these questions, students can clarify how their thoughts should be visualised or how they can be interpreted.

The norm of NR2 influenced students' drawing processes and their perceptions about scientific drawings. For example, when students were asked to suggest ways that they could improve their drawings, they considered how other people understand their drawings.

Excerpt 21 (Worksheet: How would you improve your diagrams? Why?)

G2S2: I would improve my diagrams by not doubting myself so much, thinking someone will not understand and adding many labels and information.

G1S4: Ask other people ways that it would be easier to understand.

In particular, in the above excerpt, G2S2 described that the labels explaining the symbols could help to clarify what he meant in his diagrams. This shows that visual representations complemented by other representations can help make students' drawings clearer, and the students realised this aspect was one of the ways to make drawings easier to understand.

Finally, this norm changed students' perceptions on what they considered to be good drawings. Students started to think that visualising in ways that will be easy to understand is important. When asked about what a good scientific drawing is, all but one of the students mentioned the norm of NR2.

Excerpt 22 (Questionnaire: What do you think are good scientific drawings?) 
G2S4: I think a good scientific drawing is a simple drawing that most will understand, even though not everybody will understand.

G2S4: Good diagrams have pictures that symbolise certain things that other people who were to look at the diagrams, and had no idea what the topic was.

The students' responses in Excerpts 21 and 22 indicate that students recognised that through drawings they can interact with others in ways beyond just showing their own thoughts. That is, through this norm, students realised that their drawings can be a medium to communicate their ideas.

\section{Conclusion and implication}

The purpose of this study was to investigate what norms were formed and how they emerged in making student-generated drawings through the case of one primary gifted classroom. This study reported the features of two main norms together with four sub-norms in two processes of drawing: meaning-making and representing. We described how each norm was shared and influenced students' drawings in detail. The features of the norms reported here could be summarised in terms of three aspects for supporting students to construct exploratory scientific drawings.

First, in light of understanding students' drawing processes, this study interpreted the process of constructing scientific diagrams as two inseparable processes, meaning-making and representing. The forming processes of the norms indicate how students made their explanatory meanings from scientific phenomena and how they represented meanings visually in their drawings. Furthermore, the two processes were closely connected to each other. The students made scientific drawings in interactive as well as complementary relationships of these two processes. These results show that, in order to support studentgenerated drawings, teachers need to consider at least two aspects, how to help both constructing and visualising ideas in drawings, as part of the whole drawing process. 
Second, the norms identified provided the 'desirable directions' for students to construct and visualise their ideas in scientific drawings. As the first main norm of meaningmaking processes (NM), 'explaining why' guided students how to construct their meanings in terms of showing invisible mechanisms in their diagram. To show invisible mechanisms, students were encouraged to interpret phenomena 'with key concepts (the sub-norm NM1)' at 'a particle level (the sub-norm NM2)'. As the second main norms of representing processes (NR), 'telling a story visually' led students to represent their ideas visually. For this, students documented their ideas with 'their own symbols (the sub-norm NR1)' and tried to 'make the diagrams easy to understand (the sub-norm NR2)'. Likewise, the norms played roles as navigators to lead students' development in the epistemic processes of constructing scientific drawings.

Third, the forming and sharing processes of the norms suggested how to use teaching strategies to develop students meaningfully. In this study, in terms of three essential features of norms (justifiability, sharing and behaviours), we described what are emphasised as norms, how the core ideas of each norm were shared with students and how the norms changed students' perceptions and drawings. The results indicated that, for effective teaching strategies, it is essential to share the core ideas of each strategy through various channels with students and to examine students' concrete actions reflecting the ideas. When the core ideas of teaching strategies are shared enough with students, they can influence students' drawing processes practically.

Furthermore, the results of this study build on and extend the work on multimodality in science education. Previous studies in this area (e.g., Authors, 2014; Knain, 2006; Kress, et al., 2001) have emphasised the role of sociocultural factors in the process of representation, for example, by considering the conventions associated with a particular mode of representation and the motivated interest of the sign-maker in a specific social context. 
However, few have explored how norms are formed within a shared community in the classroom. The notion of norms introduced in this study acts as an intermediary between rules and value, and provides a useful lens to understand how actions and behaviours concerning the use of drawings in explanation become norms, before they become internalised as values and beliefs around the epistemic practice of constructing explanations. Understanding this process is critical in our quest to support students in using drawings to construct scientific explanations.

As a case study, this research only focused on the cases of primary gifted students' drawings to explain physics phenomena. Thus, there are limitations to generalise the results of this study in a general context of teaching and learning scientific drawings. However, from a practical perspective, the processes of forming each norm has provided detailed ways in terms of what needs to be emphasised and how to emphasise them in making scientific drawings. In this vein, the cases of the norms reported in this study can be a foundation for establishing meaningful educational contexts specialised in student-generated drawings.

More widely, the findings of this study provide educational implications for constructing students' scientific explanations as well as student-generated drawings. Considering that the existing studies have focused more on constructing students' explanations with multiple representations (Tytler et al., 2013; Yeo \& Gilbert, 2014), this study makes contributions in this regard by describing more detailed processes of constructing and supporting students' explanations specialised in scientific drawings. Based on the results of this study, further studies are needed to explore how student-generated drawings can influence or interact with students' explanations with other multimodal representations. 
References

Author (2012).

Authors (2014a).

Authors (2014b).

Authors (2015).

Authors (2016).

Ainsworth, S., \& Th Loizou, A. (2003). The effects of self-explaining when learning with text or diagrams. Cognitive Science, 27(4), 669-681.

Ainsworth, S. (2006). DeFT: A conceptual framework for considering learning with multiple representations. Learning and Instruction, 16(3), 183-198.

Ainsworth, S., Prain, V., \& Tytler, R. (2011). Drawing to learn in science. Science, 333(6046), 1096-1097.

Becker, N., Rasmussen, C., Sweeney, G., Wawro, M., Towns, M., \& Cole, R. (2013).

Reasoning using particulate nature of matter: An example of a sociochemical norm in a university-level physical chemistry class. Chemistry Education Research and Practice, 14(1), 81-94.

Bezemer, J., \& Kress, G. (2008). Writing in multimodal texts: A social semiotic account of designs for learning. Written Communication, 25(2), 166-195.

Braaten, M., \& Windschitl, M. (2011). Working toward a stronger conceptualization of scientific explanation for science education. Science Education, 95(4), 639-669.

Brooks, M. (2009). Drawing, visualisation and young children's exploration of "big ideas". International Journal of Science Education, 31(3), 319-341.

Bruner, J. S. (1960). The process of education. Cambridge, MA: Harvard University Press.

Denzin, N. K. (2002). Interpretive interactionism (2nd ed.). London: Sage.

Duschl, R. (2008). Science education in three-part harmony: Balancing conceptual, epistemic, and social learning goals. Review of Research in Education, 32, 268-291.

Driver, R., Newton, P., \& Osborne, J. (2000). Establishing the norms of scientific argumentation in classrooms. Science Education, 84(3), 287-312.

Erickson, F. (1992). Ethnographic microanalysis of interaction. In M. D. LeCompte, W. Millroy, \& J. Preissle (Eds.), The handbook of qualitative research in education (pp. 201-225). New York, NY: Academic Press.

Glaser, B. G., \& Strauss, A. L. (1967). The discovery of grounded theory: Strategies for qualitative research. Chicago, IL: Aldine Publications. 
Horne, C. (2001). Sociological perspectives on the emergence of social norms. In M.

Hechter, \& K. D. Opp (Eds.), Social norms (pp. 1-34). New York, NY: Russell Sage Foundation.

Jewitt, C., Kress, G., Ogborn, J., \& Tsatsarelis, C. (2001). Exploring learning through visual, actional and linguistic communication: The multimodal environment of a science classroom. Educational Review, 53(1), 5-18.

Knain, E. (2006). Achieving science literacy through transformation of multimodal textual resources. Science Education, 90(4), 656-659

Kress, G., Jewitt, C., Ogborn, J., \& Tsatsarelis, C. (2001). Multimodal teaching and learning: the rhetorics of the science classroom: London: Continuum.

Lundqvist, E., Almqvist, J., \& Östman, L. (2009). Epistemological norms and companion meanings in science classroom communication. Science Education, 93(5), 859-874.

McCain, K. (2015). Explanation and the nature of scientific knowledge. Science \& Education, 24(7-8), 827-854.

Mayer, R. E. (1996). Learning strategies for making sense out of expository text: The SOI model for guiding three cognitive processes in knowledge construction. Educational Psychology Review, 8(4), 357-371.

Merriam, S. B. (1998). Qualitative research and case study applications in education. revised and expanded from "Case study research in education.". San Francisco, CA: JosseyBass Publishers.

Na, J., \& Song, J. (2014). Why everyday experience? Interpreting primary students' science discourse from the perspective of John Dewey. Science \& Education, 23(5), 10311049.

Newberry, M., \& Gilbert, J. K. (2007). Bringing learners and scientific expertise together. In K. S. Taber (Ed.), Science education for gifted learners (pp. 197-211). London: Routledge.

Quillin, K., \& Thomas, S. (2015). Drawing-to-learn: A framework for using drawings to promote model-based reasoning in biology. Life Sciences Education, 14(1), 1-16.

Peirce, C. S. (1931-1958). Collected papers of Charles Sanders Peirce (Vols. 1-8). Cambridge: Harvard University Press (C. Hartshorne, P. Weiss, \& A. W. Burks (Eds.), Vols. 1-6: A. W. Burks (Ed.), Vols. 7-8.)

Prain, V., \& Tytler, R. (2013). Representing and learning in science. In R. Tytler, V. Prain, P. Hubber, \& B. Waldrip (Eds.), Constructing representations to learn in science (pp. 114). Rotterdam: Sense Publishers. 
Sandoval, W. A. (2003). Conceptual and epistemic aspects of students' scientific explanations. The Journal of the Learning Sciences, 12(1), 5-51.

Sözen, M., \& Bolat, M. (2011). Determining the misconceptions of primary school students related to sound transmission through drawing. Procedia-Social and Behavioral Sciences, 15, 1060-1066.

Stieff, M. (2017). Drawing for promoting learning and engagement with dynamic visualizations. In R. Lowe, \& R. Ploetzner (Eds.), Learning from dynamic visualization (pp. 333-356). Springer.

Tytler, R., Hubber, P., Prain, V., \& Waldrip, B. (2013). A representation construction approach. In R. Tytler, V. Prain, P. Hubber, \& B. Waldrip (Eds.), Constructing representations to learn in science. Rotterdam: Sense Publishers.

Van Meter, P., Aleksic, M., Schwartz, A., \& Garner, J. (2006). Learner-generated drawing as a strategy for learning from content area text. Contemporary Educational Psychology, $31(2), 142-166$.

Van Meter, P., \& Garner, J. (2005). The promise and practice of learner-generated drawing: Literature review and synthesis. Educational Psychology Review, 17(4), 285-325.

Yackel, E., Rasmussen, C., \& King, K. (2000). Social and sociomathematical norms in an advanced undergraduate mathematics course. The Journal of Mathematical Behavior, 19(3), 275-287.

Yeo, J., \& Gilbert, J. K. (2014). Constructing a scientific explanation: A narrative account. International Journal of Science Education, 36(11), 1902-1935. 